Journal of Management and Bussines (JOMB)

Volume 1, Nomor 2, Desember 2019

p-ISSN : 2656-8918

e-ISSN:2684-8317

DOI : https://doi.org/10.31539/jomb.v1i2.740

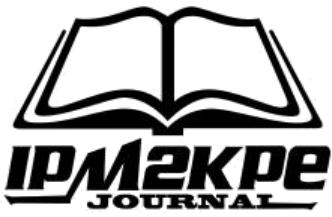

\title{
PERAN LOCUS OF CONTROL DAN STRES KERJA TERHADAP KEPUASAN KERJAKARYAWAN
}

\author{
Lisnawati $^{1}$, Acep Samsudin ${ }^{2}$, Dicky Jhoansyah ${ }^{3}$ \\ Universitas Muhammadiyah Sukabumi ${ }^{1,2,3}$ \\ Lisnaleo@ymail.com ${ }^{1}$
}

\begin{abstract}
ABSTRAK
Tujuan dari penelitian ini yaitu untuk mengukur seberapa besar pengaruh Locus Of Control dan stres kerja terhadap kepuasan kerja karyawan pada PT. Indomarco Adiprima Kota Sukabumi. Metode penelitian yang digunakan adalah metode Deskriptif dan Asosiatif. Teknik analisa yang digunakan adalah uji validitas, uji reliabilitas, analisis regresi linear berganda, termasuk uji koefisien determinasi, koefisisen korelasi ganda dan pengujian hipotesis menggunakan uji secara stimultan (Uji F). Hasil penelitian uji koefisien determinasi $\left(\mathrm{R}^{2}\right)$ locus of control dan Stres Kerja mempengaruhi sebesar 40,6\% sisa nya 59,4\% dipengaruh oleh faktor lain diluar penelitian. Simpulan, locus of control dan Stres Kerja berpengaruh signifikan terhadap Kepuasan Kerja Karyawan.
\end{abstract}

Kata Kunci : Locus Of Control, Stres Kerja, Kepuasan Kerja Karyawan

\section{ABSTRACT}

The purpose of this study is to measure how much influence the Locus of Control and job stress on employee job satisfaction at PT. Indomarco Adiprima, Sukabumi City. The research method used is descriptive and associative methods. The analysis technique used is the validity test, reliability test, multiple linear regression analysis, including the test of the coefficient of determination, multiple correlation coefficients and hypothesis testing using a stimulatory test ( $F$ test). The results of the test of the coefficient of determination (R2) Locus of Control and Work Stress affect the remaining $40.6 \%$ $59.4 \%$ influenced by other factors outside the study. Conclusions, Locus of Control and Job Stress significantly influence Employee Job Satisfaction.

Keywords: Locus of Control, Job Stress, Employee Job Satisfaction

\section{PENDAHULUAN}

Dalam sebuah Perusahaan, sumber daya manusia merupakan elemen utama yang sangat berperan bagi perkembangan dan kemajuan perusahaan agar dapat bertahan serta bersaing dalam persaingan global yang semakin kompetitif. Maka dari itu, perusahaan diharapkan untuk memperhatikan Sumber daya manusia (karyawan) yang dimilikinya. Agar produktivitas karyawan lebih meningkat, kepuasan kerja karyawan harus diperhatikan. 
Seorang karyawan yang memiliki kepuasan kerja yang tinggi menjadikan karyawan tersebut memiliki dampak positif terhadap pekerjaanya, yaitu meningkatkan produktivitas, memiliki tanggung jawab dalam berorganisasi, kesehatan fisik dan mental karyawan, sehingga karyawan akan bekerja dengan perasaan yang lebih baik dan akan terus belajar untuk mengembangkan keterampilanya.

Salah satu faktor yang mempengaruhi kepuasan kerja karyawan yaitu locus of control yang merupakan keyakinan dalam diri individu atas kemampuan yang dimiliki dan dicapai pada saat ini maupun masa yang akan datang. Beberapa hasil penelitian menunjukan bahwa locus of control dapat mempengaruhi kepuasan kerja karyawan. Salah satunya yaitu hasil penelitian yang dilakukan oleh Vindi L Wawarontu (2018) membuktikan bahwa locus of control dapat mempengaruhi kepuasan kerja karyawan.

Adanya kepuasan kerja karyawan juga dipengaruhi oleh stress kerja karyawan . Stress dalam pekerjaan terjadi ketika tuntutan pekerjaan yang terjadi tidak sesuai dengan proses regulasi mental, seperti pengolahan informasi, perencanaan dan pelaksanaan. Dalam Dina Kartikawati (2016) stress kerja memberikan pengaruh negatif terhadap kepuasan kerja karyawan dimana memiliki arti semakin tinggi stress kerja karyawan maka semakin menurun.

Tema yang diusulkan adalah peran Locus Of Control dan stress kerja terhadap kepuasan kerja pada PT. Indomarco Adiprima Kota Sukabumi. Adapun tujuan penelitian ini untuk mengetahui pengaruh Locus Of Control dan stress kerja terhadap kepuasan kerja pada PT. Indomarco Adiprima Kota Sukabumi.

\section{KAJIAN TEORI \\ Locus of Control}

Locus Of Control adalah keyakinan individu terhadap penyebab utama perilaku dan kejadian serta peristiwa dalam hidupnya, apakah disebabkan oleh faktor dalam dirinya yaitu keputusan dan keinginannya sendiri atau disebabkan oleh faktor lain di luar dirinya. Menurut Levenson (dalam Azwar, 2004) Locus Of Control adalah kecenderungan pusat kendali individu yang dikenal juga dengan kecenderungan arah atribusi. Dimensi locus of control Levenson (dalam Azwar, 2004) Levenson memberikan tiga dimensi locus of control yaitu internality, chance dan powerful others. 


\section{Dimensi internality}

Adalah keyakinan seseorang bahwa kejadian-kejadian dalam hidupnya ditentukan terutama oleh kemampuan dirinya sendiri seperti keterampilan dan potensipotensi yang dimilikinya. Internality termasuk ke dalam Locus Of Controlinternal karena pada dimensi ini individu melihat bahwa dirinya sendiri bertanggungjawab terhadap peristiwa yang terjadi dalam hidupnya.

\section{Dimensi chance (kesempatan)}

Dimensi chance (kesempatan) yaitu keyakinan seseorang bahwa kejadiankejadian dalam hidupnya ditentukan terutama oleh nasib, peluang dan keberuntungan. Termasuk kedalam Locus Of Control eksternal karena dimensi ini individu melihat bahwa kejadian dalam hidupnya di pengaruhi oleh faktor yang berada di luar dirinya yaitu nasib dan keberuntungan.

\section{Dimensi powerful others (dukungan dari luar)}

Adalah keyakinan seseorang bahwa kejadian-kejadian dalam hidupnya ditentukan terutama oleh orang lain yang lebih berkuasa. Termasuk kedalam Locus of Control eksternal karena dimensi ini individu melihat bahwa kejadian dalam hidupnya di pengaruhi oleh faktor yang berada di luar dirinya yaitu orang lain yang lebih berkuasa.

\section{Stres Kerja}

Stress kerja merupakan suatu tanggapan penyesuaian yang diperantarai oleh perbedaan-perbedaan individu atau proses psikologis.adanya perbedaan kemampuan individu dengan tuntutan pekerjaan akan menimbulkan stress kerja.

Stres kerja (Gibson, 1996) suatu tanggapan penyesuaian diperantarai oleh perbedaan-perbedaan individu atau proses psikologis. Akibat dari setiap tindakan lingkaran, situasi atau pristiwa yang menetapkan permintaan psikologi atau fisik pada seseorang. 
Menurut Cousins et al. (2004) dalam Edwards et al (2008) terdapat tujuh

Dimensi utama indikator stres kerja yaitu :

1. Tuntutan. Kondisi yang mencakup isu-isu seperti beban kerja, pola kerja dan lingkungan pekerjaan yang dihadapi.

2. Kontrol. Terkait dengan sejauh mana perusahaan melakukan pengawasan terhadap karyawannya.

3. Dukungan rekan. Yaitu sejauh mana rekan kerja memberikan dukungan terkait dengan pekerjaan.

4. Dukungan manajerial. Berkaitan dengan sejauh mana manajemen perusahaan memberikan dukungan kepada karyawan berupa penghargaan atau hal lain.

5. Hubungan. Berkaitan dengan hubungan yang terjalin di dalam organisasi atau perusahaan, baik antar pekerja maupun dengan atasan, misalnya apakah kerjasama, konselor, ketidakpahaman instruksi, kesulitan untuk fokus, dan tidak adanya kesesuaian karena bekerja terlalu lama.

6. Peran. Dalam hal ini apakah karyawan memahami peran mereka dalam organisasi dan apakah organisasi memastikan mereka tidak memiliki peran yang saling bertentangan

7. Perubahan. Yaitu bagaimana organisasi mengelola dan mengomunikasikan perubahan yang terjadi.

\section{Kepuasan Kerja Karyawan}

Kepuasan kerja yaitu suatu perasaan perasaan pegawai sebagai perbedaan antara banyaknya ganjaraan yang diterima dengan yang seharusnya diterima. Kepuasan kerja (Robbins 2015) adalah suatu sikap umum terhadap pekerjaan seseorang sebagai perbedaan antara banyaknya ganjaran yang diterima pekerja dengan banyaknya ganjaran yang diyakini seharusnya diterima.Menurut Neog, Barua (2014) kepuasan kerja diterapkan meliputi 4 faktor yaitu:

1. Kompensasi. Kompensasi merupakan salah satu variabel yang paling utama bagi kepuasan kerja karyawan.

2. Dukungan atasan dukungan. Atasan adalah salah satu faktor penting untuk karyawan, dukungan atasan didefinisikan dengan sejauh mana para pemimpin peduli tentang kesejahteraan karyawan mereka dan menghargai kontribusi mereka. 
3. Lingkungan kerja . Pekerja lebih sangat peduli dengan keadaan lingkungan kerja yang nyaman agar dapat bekerjnya dengan baik dan menginginkan kondisi kerja yang aman seperti temperatur, cahaya, keramaian dan faktor lainya.

4. Keamanan kerja. Keamanan kerja merupakan Faktor sebagai penunjang kepuasan kerja yang baik bagi karyawan. Keadaan yang aman sangat mempengaruhi perasaan karyawan selama kerja. Keamanan dalam bekerja cenderung membuat karyawan merasa puas dengan pekerjaannya.

Untuk memperkuat penelitian, maka teori yang menyatakan bahwa antar variable berpengaruh adalah penelitian Vindi L wawarontu (2018) menyatakan bahwa adanya pengaruh yang signifikan dari variabel Locus Of Control dengan kepuasan kerja.

Sedangkan keterkaitan stress kerja dengan kepuasan kerja menurut Dina Kartikawati (2016) stress kerja memberikan pengaruh negatif terhadap kepuasan kerja karyawan dimana memiliki arti semakin tinggi stress kerja karyawan maka semakin menurun.

\section{METODE PENELITIAN}

Penelitian ini dilaksanakan di PT. Indomarco Adiprima Kota Sukabumi. Metode penelitian yang digunakan adalah deskriptif dan Asosiatif. Sampel yang digunakan dalam penelitian ini adalah menggunakan jenis sampling jenuh yang termasuk kedalam non-probabilitysampling dengan melakukan penyebaran kuisioner kepada 32 orang karyawan pada PT. Indomarco Adiprima Kota Sukabumi. Teknik analisa yang digunakan adalah uji validitas, uji reliabilitas, analilis regresi linear berganda, termasuk uji koefisien determinasi, koefisien korelasi ganda, dan pengujian hipotesis menggunakan uji secara stimultan (uji F)

\section{HASIL PENELITIAN}

\section{Uji Validitas}

Tabel 1 Hasil Uji Validitas

\begin{tabular}{ccccc}
\hline Variabel & Item & r- hitung & r- kritis & Keterangan \\
\hline \multirow{2}{\text{Locus}\text{Of}}{\begin{tabular}{c} 
Control (X1) \\
\cline { 2 - 5 }
\end{tabular}} & 2 & 0,425 & 0,3 & Valid \\
\cline { 2 - 5 } & 3 & 0,544 & 0,3 & Valid \\
\hline
\end{tabular}




\begin{tabular}{ccccc}
\hline & 4 & 0,337 & 0,3 & Valid \\
\hline & 1 & 0,695 & 0,3 & Valid \\
\cline { 2 - 5 } & 2 & 0,609 & 0,3 & Valid \\
\cline { 2 - 5 } Stres kerja(X2) & 3 & 0,359 & 0,3 & Valid \\
\cline { 2 - 5 } & 5 & 0,377 & 0,3 & Valid \\
\cline { 2 - 5 } & 6 & 0,646 & 0,3 & Valid \\
\hline $\begin{array}{c}\text { Kepuasan } \\
\text { Kerja }\end{array}$ & 2 & 0,340 & 0,3 & Valid \\
\cline { 2 - 5 } \begin{tabular}{c} 
Karyawan (Y) \\
\cline { 2 - 5 }
\end{tabular} & 3 & 0,802 & 0,3 & Valid \\
\cline { 2 - 5 } & 4 & 0,816 & 0,3 & Valid \\
\hline
\end{tabular}

Sumber : Data Primer(Kuesioner), 2019

Berdasarkan data tabel diatas, dapat diketahui bahwa nilai korelasi antara skor item variabel Locus Of Control (X1), Stres Kerja (X2) dan Kepuasan Kerja Karyawan (Y) bahwa seluruh item pada hasil pengujian tersebut memiliki skor diatas 0,3 sehingga seluruh butir instrumen itemLocus Of Control (X1), Stres Kerja (X2) dan Kepuasan Kerja Karyawan (Y) dinyatakan valid.

\section{Uji Reliabilitas}

Tabel 2 Hasil Uji Reliabilitas

\begin{tabular}{cccc}
\hline \multirow{2}{*}{ Variabel } & \multicolumn{2}{c}{$\begin{array}{c}\text { Koefisien } \\
\text { Cronbach's Alpha }\end{array}$} & Keterangan \\
\cline { 2 - 3 } & Hitung & Standar & \\
\hline Locus Of Control (X1) & 0,456 & 0,3 & Reliabel \\
\hline Stres Kerja (X2) & 0,683 & 0,3 & Reliabel \\
\hline Kepuasan Kerja Karyawan (Y) & 0,754 & 0,3 & Reliabel \\
\hline
\end{tabular}

Sumber: Data Primer (Kuesioner), 2019

Dari tabel 2 di atas diperoleh hasil yang menunjukkan bahwa nilai $\alpha$ hitung $>\alpha$ standar $(0,3)$ sehingga dapat disimpulkan bahwa variabel-variabel yang dipakai dalam penelitian ini adalah reliabel. Dengan demikian maka jelaslah bahwa variabel-variabel tersebut dapat digunakan untuk penelitian selanjutnya karena dapat diandalkan. 


\section{Koefisien Korelasi Ganda}

Tabel 3 Hasil Koefisien Korelasi Ganda

\begin{tabular}{|c|c|c|c|c|}
\hline \multicolumn{5}{|c|}{ Model Summary } \\
\hline Model & $\mathrm{R}$ & R Square & $\begin{array}{l}\text { Adjusted R } \\
\text { Square }\end{array}$ & $\begin{array}{l}\text { Std. Error of the } \\
\text { Estimate }\end{array}$ \\
\hline 1 &, $637^{\mathrm{a}}$ &, 406 &, 365 &, 787 \\
\hline a. Pred & (Constan & , Locus Of & ntrol,Stres Kerj & \\
\hline
\end{tabular}

Berdasarkan tabel 3 diatas diperoleh angka $\mathrm{R}$ sebesar 0,637 berada pada kategori 0,60-0,799. Hal ini menunjukkan bahwa terjadinya hubungan yang kuat antara Locus Of Control dan Stres Kerja terhadap Kepuasan Kerja Karyawan.

\section{Koefisien Determinasi $\left(\mathbf{R}^{2}\right)$}

Tabel 4 Hasil Koefisien Determinasi

\begin{tabular}{lccccc}
\hline \multicolumn{5}{c}{ Model Summary } \\
\hline Model & $\mathrm{R}$ & R Square & $\begin{array}{c}\text { Adjusted R } \\
\text { Square }\end{array}$ & $\begin{array}{c}\text { Std. Error of the } \\
\text { Estimate }\end{array}$ \\
\hline 1 &, $637^{\mathrm{a}}$ &, 406 &, 365 &, 787 \\
\hline a. Predictors: (Constant), Locus Of Control,Stres Kerja & \\
\hline Sumber: Data Primer (Kuesioner),2019 &
\end{tabular}

Berdasarkan hasil tabel 4 diatas model summary menyatakan besarnya adjusted $\mathrm{R}^{2}$ sebesar 0,406; hal ini berarti 40,6\% variasi Kepuasan kerja karyawan dapat dijelaskan oleh variasi dari dua variabel independen yaitu locus of control dan efikasi stres kerja. Sedangkan sisanya 59,4\% $(100 \%-40,6 \%=59,4 \%)$ dari faktor yang tidak diteliti.

\section{Hasil Analisis Regresi Linear Berganda}

Tabel 5 Hasil Analisis Regresi Linear Berganda

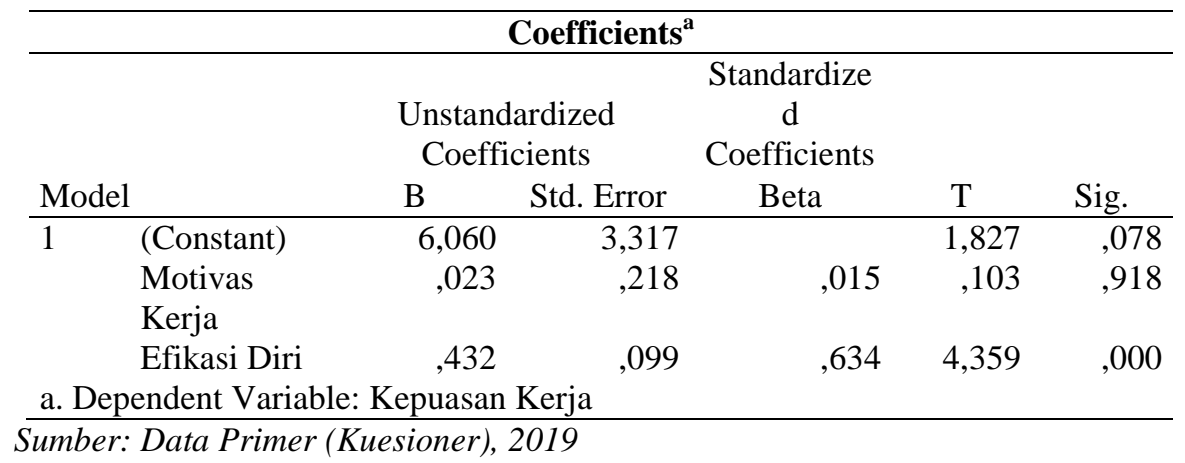


Dari output uji regresi linear berganda diatas, maka dapat diperoleh persamaan sebagai berikut :

$$
Y=6,060+0,023 X_{1}+0,432 X_{2}
$$

\section{Uji Signifikan Secara Simultan (Uji F)}

Tabel 6 Hasil Uji F

\begin{tabular}{|c|c|c|c|c|c|c|}
\hline \multicolumn{7}{|c|}{ ANOVA $^{a}$} \\
\hline Model & & Sum of Squares & Df & Mean Square & $\mathrm{F}$ & Sig. \\
\hline \multirow[t]{3}{*}{1} & Regression & 12,270 & 2 & 6,135 & 9,913 &, $001^{\mathrm{b}}$ \\
\hline & Residual & 17,948 & 29 & 619 & & \\
\hline & Total & 30,219 & 31 & & & \\
\hline \multicolumn{7}{|c|}{ a. Dependent Variable: Kinerja Karyawan } \\
\hline \multicolumn{7}{|c|}{ b. Predictors: (Constant), Efikasi Diri, Motivas Kerja } \\
\hline
\end{tabular}

Berdasarkan Tabel 6 di atas, hasil uji F yang dilakukan dapat diperoleh nilai Sig. $0,001<0,05$; nilai $F_{\text {hitung }} 9,913>\mathrm{F}_{\text {tabel }} 3,33$. Artinya bahwa locus of control dan Stres Kerja berpengaruh positif dan signifikan terhadap Kepuasan Kerja Karyawan.

Dari hasil hitungan penelitian analisis regresi berganda dengan uji $\mathrm{F}$ dengan tingkat signifikan sebesar 5\% $(0,05)$ menunjukkan bahwa locus of control dan Stres Kerja berpengaruh terhadap kepuasan kerja karyawan secara bersama-sama terhadap kepuasan kerja karyawan. hal ini di tunjukkan dari hasil nilai Sig. 0,001<0,05; nilai $\mathrm{F}$ hitung 9,913> $\mathrm{F}_{\text {tabel }}$ 3,33. Nilai koefisien determinasi $\left(\mathrm{R}^{2}\right)$ dari Locus Of Control dan Stres Kerja mempengaruhi sebesar $40,6 \%$ sisa nya $59,4 \%$ dipengaruh oleh faktor lain diluar penelitian. Hal ini dikarenakan suatu locus of control dan stres kerja berperan penting dalam meningkatkan kepuasan kerja karyawan. dengan demikian dapat diketahui bahwa locus of control dan Stres Kerja merupakan faktor yang membentuk kepuasan kerja karyawan pada PT. Indomarco Adiprima Kota Sukabumi.

\section{PEMBAHASAN}

\section{Pengaruh Locus of Control terhadap Kepuasan Kerja}

Diketahui bahwa variable locus of control memiliki pengaruh yangsignifikan terhadap kepuasan kerja karyawan pada PT. Indomarco Adiprima Kota Sukabumi. Dapat dilihat dari tanggapan responden yang tinggi mengenai kepuasan karyawan terhadap diri sendiri. Seseorang yang memiliki kepuasan terhadap diri sendiri akan 
memiliki perasaan-perasaan positif mengenai pekerjaanya sehingga kepuasan kerja akan meningkat. Sebagaimana yang diungkapkan oleh Vindi L Wawarontu (2018) bahwa adanya pengaruh yang signifikan antara variabel locus of control dengan kepuasan kerja.

\section{Pengaruh Stres Kerja terhadap Kepuasan Kerja}

Diketahui bahwa variabel stres kerja memiliki pengaruh yang positif terhadap kepuasan kerja karyawan pada PT. Indomarco Adiprima Kota Sukabumi. Dapat dilihat dari tanggapan responden yang tinggi mengenai kepuasan karyawan terhadap dukungan manajerial dan perubahan yang terjadi. Stres Kerja yang terdapat pada batasan tertentu dapat meningkatkan kepuasan kerja sebagaimana yang diungkapkan Torman Romanco Sormin (2017) stress kerja memberikan pengaruh yang positif terhadap kepuasan kerja karyawaan. Semakin tinggi stress kerja maka semakin tinggi kepuasan kerja karyawan.

\section{SIMPULAN}

Tiap-tiap indikator dari masing-masing variable locus of control (X1), Stres Kerja (X2) dan Kepuasan Kerja Karyawan (Y) dalam penelitian ini dapat mewakili dari masing-masing variabelnya dan sekaligus dapat dihandalkan untuk dipergunakan sebagai indikator yang dapat digunakan oleh peneliti yang akan mendatang. Berdasarkan uji F, variabel locus of control dan Stres Kerja berpengaruh positif dan signifikan terhadap Kepuasan Kerja Karyawan PT. Indomarco Adiprima Kota Sukabumi.

\section{DAFTAR PUSTAKA}

Azwar, S. (2004). Pengantar Psikologi Inteligensi. Cetakan Keempat. Pustaka Pelajar, Yogyakarta

Edwards, J. A., Webster, S., Laar, D. V., \& Easton, S. (2008). Psychometric Analysis of the UK Health and Safety Executive's Management Standards Work-Related Stress Indicator Tool. Work \& Stress. An International Journal Of Work, Health \& Organisations. 22(2)

Gibson, G., James, L. (1996). Organisasi: Perilaku, Struktur, Proses. Diterjemahkan oleh Ninuk Adriani. Jakarta: Binarupa Aksara

Karikawati, D. (2016). Pengaruh Stres Kerja terhadap Kepuasan Kerja Karyawan pada PT. Sri Rejeki Isman Textile Sukoharjo. Skripsi. Universitas Muhammadiyah Surakarta

Neog, B. B., Barua, M. (2014). Factor Influencing Employee's Job Satisfaction: An Empirical Study among Employees of Automobile Service Workshops in Assam. 
The SIJTransactions on Industrial, Financial \& Buisness Management (IFBM), 2(7), 305-316

Robbins, S. P., Judge T. A. (2015). Perilaku Organisasi. Jakarta: Salemba Empat

Sormin, T. R., Anisah, H.U., \& Dewi, M.S. (2017). Pengaruh Stress Kerja terhadap Kepuasan Kerja serta Dampaknya terhadap Kinerja Karyawan. Jurnal Wawasan Manajemen, 5

Waworuntu, L. V., \& Adolfina, A. (2018). Pengaruh Locus of Control dan Kepuasan Kerja terhadap Prestasi Kerja. Jurnal EMBA, 1468-147796-107 